\title{
Needs of carers of people with long-term mental illness in Mid Glamorgan
}

\author{
David Cohen and Lisa Thomas
}

\begin{abstract}
In recent years, the core of people with long-term and persistent mental illness has been shiting from Insttutional to community care with a consequent increase in the use of informal carers. Given that both probsedonals and carers are human resources contributing to the health and well-being of patients, It is surprting thet so litte resecerch on the needs of corers or means to improve their effectiveness has been undertaken.
\end{abstract}

The limited research conducted on carers of patients with long-term and persistent mental illness has shown that carers often bear a great psychological/emotional burden (Atkinson, 1991: Hall \& Pieri, 1992; Sargent, 1993), suffer considerable economic losses (Kelling, 1993), have a wide range of needs (Mullen \& Kuipers. 1992) and are dissatisfied with the information given to them by health professionals on both the condition and management of the patient (Atkinson, 1991; Holden \& Levine, 1982).

\section{The study}

The aim of the study was to determine the extent to which the needs of carers of patients with longterm or persistent mental illness in one Health District were being met, how carers viewed the services they received, and what additional inputs were required to more fully meet their needs.

Although carers were the object of interest, we felt it would not be ethical to approach them directly. Accordingly, we chose first to contact patients and seek their consent to approach their carers. This inevitably produced a smaller sample of carers than could have been possible using more direct methods.

We intended to contact all patients in Mid Glamorgan with long-term and persistent mental illness, defined as having been on a consultant psychiatrist's out-patient list for over one year. We felt that any concern by patients about the motives behind the study would be minimised if a letter of support from their own consultant psychiatrist accompanied the letter requesting their cooperation.

Carers so identified were sent a questionnaire covering personal details, use of and views on professional help, use of and views on carer support groups, additional support wanted, and burden of caring on carer/family.

Because of the impersonal nature of postal questionnaires we felt that the individuality of each case could only be appreciated through face to face interviews which would also give carers the opportunity to expand on issues raised in the questionnaire and to highlight areas of their caring role and service provision that they considered to be important. Interviews were carried out by a qualified social worker.

We identified 365 patients who met the above criteria. As we were unsuccessful in obtaining written letters of support from all consultant psychiatrists, only 290 letters to patients were posted. Eighty-two replies named a carer (response rate $=28 \%$ ). All 82 were sent the questionnaire and 32 were returned (response rate $=39 \%)$. Nine $(28 \%)$ agreed to be interviewed.

We also wished to explore the possibility that 'active' carers - those in regular contact with the National Schizophrenia Fellowship (NSF) and who had been used as 'representative carers' might have different perceptions from those identified by our study method. Four such carers were sent questionnaires on different coloured paper. All agreed to be interviewed. In the event their responses on both questionnaire and interview were indistinguishable from the others, suggesting that they were truly 'representative'. Accordingly we felt that we could add their responses to the others to bring the questionnaire sample to 36 and interview sample to 13.

\section{Findings}

Questionnaire $(\mathrm{n}=36)$

The majority of carers were middle-aged or elderly, caring for immediate family members. Twenty-nine were aged 40 and over (13 aged 60 
and over) and only three were under 30 . Thirty of the 36 were parent, spouse or child of the patient they cared for.

Most carers lived with the person that they cared for. Of the 11 who did not, only three lived more than five miles away. Seven of these 11 still visited the patient at least once every day and all visits lasted over one hour.

Roughly half of all carers received professional help from social workers and/or community psychiatric nurses in their role as carers. Of the 17 who did not, six indicated that they would like such support while the remaining nine were happy to continue caring without professional help.

Twenty-four carers were unaware of the existence of carer self-help groups. Of the 12 who were aware, only four attended meetings. The main reasons for not attending (apart from nonawareness) were a dislike of group meetings (9), lack of time (4) and lack of transport (4).

With regard to types of support wanted, carers were asked to identify as many as they liked from a list. More professional help (10 responses), home visits from someone who understands (10), a 24 hour help/support line (9) and facilities to allow breaks (8) were the most commonly identified services. Only four carers identified night sitters to allow them to go out in the evening as a needed service.

Of the 35 who answered the questions on employment, only seven were in paid employment and two of these were working reduced hours because of demands on them as carers. Of the 28 not in work, 19 had not worked before becoming carers while eight had given up work completely to become carers.

\section{Interviews ( $\mathrm{n}=13)$}

Interviewees had to be repeatedly reminded that the study was concerned with their own needs, rather than those of the patient.

Views on current professional support were mixed. Eight of the 13 interviewees received regular help from a community psychiatric nurse and two from a social worker - although these visits were primarily to help the patient. Five received no professional support of any kind, despite four of them indicating a need.

Most emphasised how the care they gave was a 24 hour, seven days a week activity and expressed dissatisfaction with professional support being restricted to Monday-Friday 9.00 5.00. The most frequently requested form of support was a 24 hour telephone helpline. There was also a clearly expressed need for training, for example in how to respond when the patient became violent.

There was a clear expression of a need for longer-term input by designated social workers, rather than just an initial visit as at present. Several carers felt that the different professionals did not appear to share information, and found themselves constantly repeating the same details.

Regarding services to ease the burden of caring. respite care was frequently mentioned. This included work projects and day centres for patients as well as night sitters, although most carers stressed that they would only be happy leaving the patient with qualified professionals. Surprisingly, help in dealing with insurance claims was frequently mentioned as many had experienced problems with insurance companies who were reluctant to pay out on policies following an episode of destruction by the patient.

The need for various types of information was mentioned by all interviewees. This included information about available support services and benefits to which they were entitled, as well as information about mental health generally. Additionally, many called for information to the public to raise awareness and understanding of mental illness.

Regarding their own health, all felt that caring was stressful and most believed that their own physical well-being had been affected by their role as carer. Many had little or no social life and most felt isolated from the world outside, often because of fear of the self-harm or property damage that the patient might do if left alone. Only one carer who did not live with the patient - said that he had not let his role as carer interfere with social life.

Two interviewees gave up work completely because of the demands of caring. A further two took early retirement because their own health was deteriorating as a consequence of the stress caused by caring. Four others said caring had an adverse effect on the standard of their work. Five did not work prior to becoming a carer. One had to give up her course at the local college.

All thought Community Care was a good idea in principle but there was a clear overall feeling that there was not enough support for the concept to work well in practice.

\section{Comment}

Questionnaire and interview results both support the findings of previous research in the area; carers bear a high emotional and economic burden, are generally dissatisfied with the professional support and information they currently receive, and have a wide range of demands which are either not met to the extent demanded, or not at all.

The interviews added a personal and human dimension to caring which was inevitably absent from the questionnaire responses. Each interviewee had a tale to tell which emphasised the 
extent of the burden they bore and left a clear impression that caring affected most if not all aspects of their lives.

Perhaps the most striking observation was the difficulty interviewees found in not discussing the patient's needs despite being reminded repeatedly that the study was about their own needs as carers. While this can be interpreted as carers putting the patients' needs above their own, the impression was much more that the two are to a large extent inseparable. Better professional services to patients appeared to be the most effective way of meeting the needs of carers.

\section{References}

ATKinson, J. (1991). Carers, the community and the White Paper. Psychiatric Bulletin. 18. 763-764.

HALL. D. J. \& PIER, L. F. (1992) Audit in practice - providing a community mental handicap service. Psychiatric Bulletin. 16. 20-21.

HOLDEN, D. F. \& LEWINE, R. R. J. (1982) How families evaluate mental health professionals. resources and effects on illness. Schizophrenia Bulletin, 8, 626-633.

Kelung, K. (1993) Caring costs. Carers, 1. 2-3.

MULLEN, R. \& KUIPERS, L. (1992) A workshop for the relatives of people with chronic mental illness. Psychiatric Bulletin. 16. 206-207.

SARGENT, R. (1993) Schizophrenia - the problem for the family. Psychiatric Bulletin, 17, 14-15.

*David Cohen, Professor: and Lisa Thomas, Research Assistant, University of Glamorgan Business School, Pontypridd CF37 IDL

*Correspondence

\section{Acknowledgements}

The authors would like to thank Deborah Smith who conducted the interviews. Also Ian Isaac, Area Manager, NSF (Wales) and Gordon Jones, Principal Officer, Mid Glamorgan Social Services who managed and resourced the project. Thanks also to Dr Anthony Williams and all other participating consultant psychiatrists.

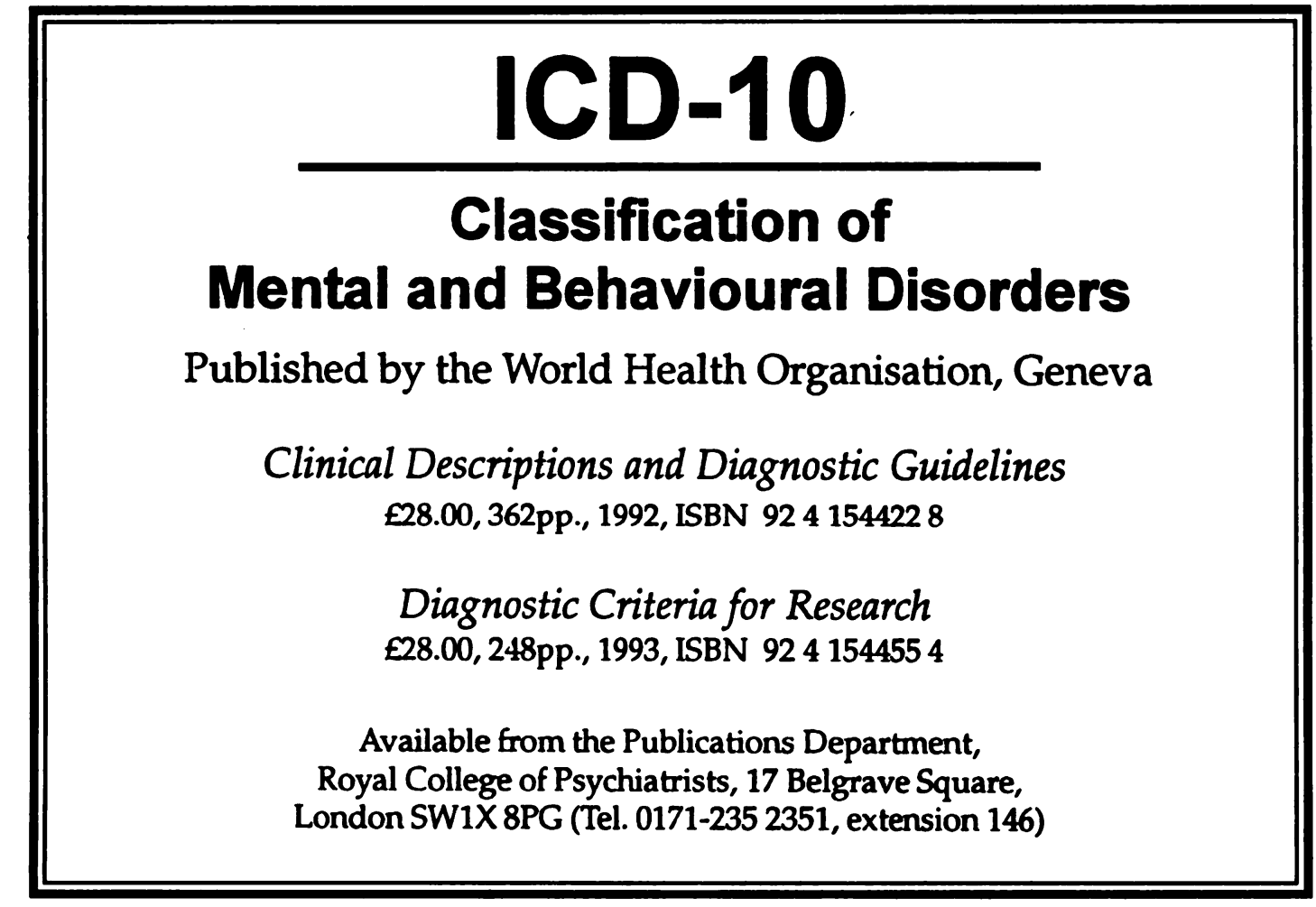

